\title{
PRIMARY HYDATID CYST OF BROAD LIGAMENT
}

\author{
Valsa Diana $G^{1}$, M. Padmini
}

${ }^{1}$ Senior Consultant, Rajiv Gandhi Govt. Women and Children Hospital. 2Medical Officer, Rajiv Gandhi Govt. Women and Children Hospital.

HOW TO CITE THIS ARTICLE:Diana VG, Padmini M. Primary hydatid cyst of broad ligament. J. Evolution Med. Dent. Sci. 2018;7(05):700-701, DOI: $10.14260 /$ jemds/2018/158

\section{PRESENTATION OF CASE}

A 50-year-old perimenopausal lady from Villivakkam village, of Kanchipuram district presented with complaints of mass per abdomen since 2 years and lower abdominal pain. She was menstruating regularly. No history of contact with dog or other pet animal could be obtained.

\section{DIFFERENTIAL DIAGNOSES}

- Pregnancy.

- Pedunculated fibroid.

- Paraovarian cyst.

- Malignant multicystic ovarian tumour.

\section{CLINICAL DIAGNOSIS}

- On general examination the lady was thin built, moderately nourished and not anaemic. There was no lymphadenopathy.

- $\quad$ On systemic examination, respiratory and cardiovascular systems were normal.

- On abdominal examination, a soft lobulated irregular mass of 20 weeks arising from the pelvis and occupying hypogastrium. There was no hepatosplenomegaly or ascites. Bimanual examination located the mass in left fornix.

- Routine blood and urine examination, and chest x-ray revealed no abnormality.

- $\quad$ Serum CA-125 (cancer antigen), AFP (alpha-fetoprotein), CEA (carcinoembryonic antigen) were within normal limits.

- Ultrasonography (USG) of whole abdomen suggested a complex multicystic lesion with multiple septations measuring $15.2 \times 11.7 \mathrm{~cm}$ mass more on the left side with small speck of calcification and no solid component.

- CT scan abdomen showed hypodense cystic lesion measuring $14.1 \times 10.2 \mathrm{~cm}$ in the middle of pelvis extending upto infraumbilical region having multiple septations within and calcifications in the wall.

\section{PATHOLOGICAL DISCUSSION}

- Intraoperatively, right broad ligament cyst of size $15 \mathrm{x}$ $10 \mathrm{~cm}$ was present. Uterus, both tubes and ovaries were normal. During surgery, the cyst ruptured and multiple hydatid cysts came out. The whole cyst with its wall excised, TAH + BSO done and sent for histopathological examination.

'Financial or Other Competing Interest': None.

Submission 22-12-2017, Peer Review 15-01-2018,

Acceptance 22-01-2018, Published 29-01-2018.

Corresponding Author:

Dr. Valsa Diana $G$

NO. 13, 1st Cross,

Aziz Nagar, Reddiyarpalem

E-mail: valsadiana@gmail.com

DOI: $10.14260 / j e m d s / 2018 / 158$

(c) (i) $(9)$
- On gross examination of specimen, an elongated cyst measuring $15 \times 10 \mathrm{~cm}$ on the right side of uterus from the broad ligament. On opening, albuminous egg white membrane like structure came out.

- Microscopic examination revealed a cyst wall composed of lamellated ectocyst with chronic inflammatory cell in pericyst, consistent with the diagnosis of hydatid cyst of broad ligament.

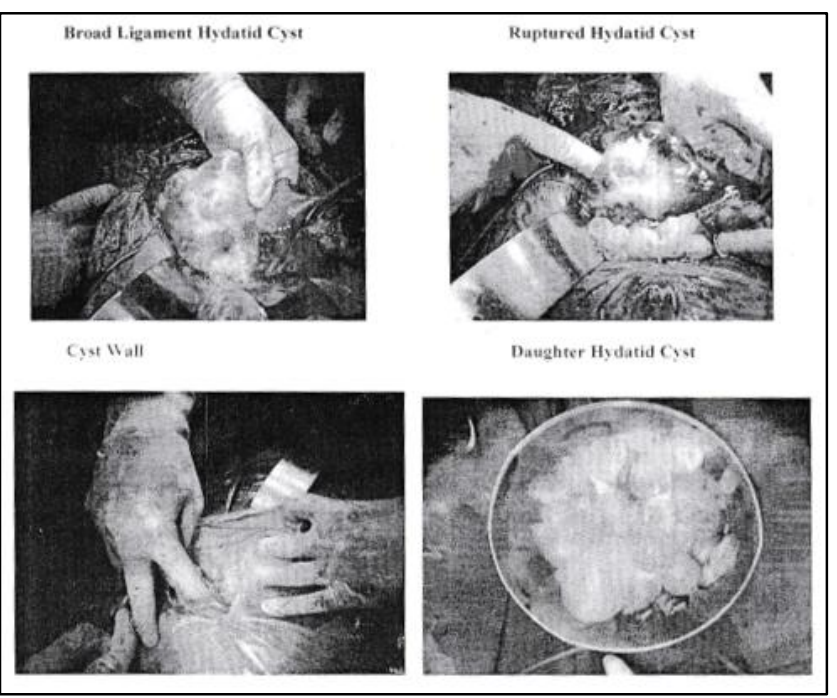

\section{DISCUSSION OF MANAGEMENT}

Apart from Surgery, three other modalities are established:[1]

- Chemotherapy with albendazole/mebendazole.

- Percutaneous drainage sterilisation (PAIR).

- Observation of inactive echinococcal stages 'watch and wait' approach.

In our case, as the diagnosis was incidental, pre-operative medication with albendazole was not possible; hence, surgery followed by chemotherapy with albendazole was the treatment of option.

\section{FINAL DIAGNOSIS}

Pre-operative diagnosis of primary pelvic hydatidosis may be difficult, as the lesion mimics malignancy.[2] A preliminary diagnosis by cytology or FNAC (fine needle aspiration cytology) may not always be helpful, as thick mucin aspirated with scanty cellularity may simulate laminated membrane of hydatid cyst and easily misdiagnosed as ectocyst of hydatid disease.[3] In our case FNAC was not done, as there was no suspicion of hydatid cyst in pelvic region.

Diagnosis of hydatid cyst of female pelvic organ is usually possible only after operation.[4] In our case also it was diagnosed only after exploratory laparotomy, which was carried out with provisional diagnosis of right-sided ovarian tumour. 
However, pre-operative diagnosis of pelvic hydatid diseases can be possible with imaging study such as USG, CT scan by noting features such as multilocular appearance, cyst wall calcification, a fluid level from hydatid sand and the ultrasonic water lily sign.[5] However, in the present case, USG and CT scan could not detect such abnormality. According to Gharbi's classification Type 1 Cystic Echinococcosis (CE) and World Health Organisation, Type $1 \mathrm{CE}$, present as unilocular cystic lesion with an anechoic content which is similar to our case. Non-complicated isolated Type 1 pelvic CE mimicking ovarian tumour Type $1 \mathrm{CE}$ is a diagnostic dilemma as diagnostic criteria of advanced disease are not seen in Type 1.[6] The condition was identified postoperatively with gross and histopathological examination of cyst. Therefore, a high degree of clinical suspicion is essential in the differential diagnosis of pelvic cystic diseases.

\section{REFERENCES}

[1] Hosch W, Junghanss T, Werner J, et al. Imaging methods in the diagnosis and therapy of cystic echinococcosis. Rofo 2004;176(5):679-87.

[2] Varedi P, Saadat Mostafavi SR, Salouti R, et al. Hydatosis of the p cavity: a big masquerade. Article ID 782621, Infect Dis Obstet Gynecol 2008;2008: p. 3.

[3] Godara R, Dhingra A, Ahuja V, et al. Primary peritoneal hydatidosis: clinically mimicking carcinoma ovary. Internet J Gynecol Obstet 2007;7(2):1-4.

[4] Arora M, Gupta CR, Jindal S, et al. An unusual case of broad ligament. JIACM 2005;6(1):86-7.

[5] Pedrosa I, Saiz A, Arrazola J, et al. Hydatid disease: radiologic and pathologic features complications. Radiographics 2000;20(3):795-817.

[6] Vural M, Yalcin S, Yildiz S, et al. Isolated type 1 pelvic cystic echinococcosis mimicking ovarian tumor. $\mathrm{N}$ Am J Med Sci 2011;3(6):289-91. 